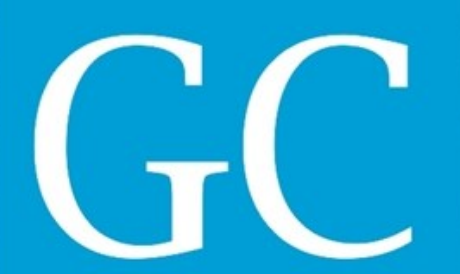

Revista Nacional de

ISSN 2318-8472

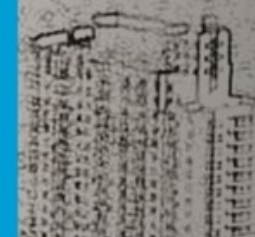

\title{
Estudos Culturais da Paisagem: Canafístula Esplendor Cultural
}

Cultural Studies Landscape: Canafístula Cultural Splendor

Los estudios Culturales Paisaje: Canafístula Esplendor Cultural

Anderson Miranda dos Santos

Professor Mestre, UFRJ, Brasil

miranda-lampiao@hotmail.com 


\section{RESUMO}

O trabalho procura estudar as relações das manifestações dos folguedos que ocorrem no bairro Canafístula, na cidade de Arapiraca-Alagoas, e a paisagem, considerando as possíveis interações entre os espaços livres e a cultura popular. Propõe uma restruturação dos espaços livres do bairro, considerando-os como elementos estruturadores da paisagem, valorizando áreas com efervescência cultural que se encontram fragmentadas. As abordagens associadas aos espaços livres (socioculturais: preservação dos processos sociais e manifestações culturais) agregam valores com o potencial de promover a conexão entre áreas verdes e atividades culturais, favorecendo a convivência coletiva na paisagem e a permanência dos folguedos existentes. Objetiva-se, portanto, propor uma sistematização dos espaços livres públicos para atender a uma demanda histórica e cultural de uso coletivo, explorando as relações socioespaciais dos folguedos com o bairro e a cidade, com intuito de contribuir para salvaguardar as manifestações culturais do bairro e assim adequar à condição de recuperação urbana em que a área se depara hoje em dia.

PALAVRAS-CHAVE: Paisagem. Espaços Livres. Folguedos.

\section{ABSTRACT}

The work seeks to study the relationships of expressions of folguedos that occur in Canafístula neighborhood in the city of Arapiraca-Alagoas, and the landscape, considering the possible interactions between the open spaces and popular culture. It proposes a restructuring of the open spaces in the neighborhood, considering them as structural elements of the landscape, highlighting areas with cultural effervescence that are fragmented. Approaches associated with open space (sociocultural: preservation of social processes and cultural events) add value with the potential to promote the connection between green areas and cultural activities, promoting living together in the landscape and the permanence of existing folguedos. The purpose is therefore to propose a systematization of public open spaces to serve a historical and cultural demand for collective use, exploring the socio-spatial relations of folguedos with the neighborhood and the city, in order to contribute to safeguarding the cultural events of the neighborhood and thus tailor the urban recovery condition in which area faces today.

KEYWORDS: Landscape. Open spaces. Folguedos.

\section{RESUMEN}

El trabajo pretende estudiar las relaciones entre los "Folguedos" (Manifestaciones culturales que se producen en el barrio Canafístula en la ciudad de Arapiraca, Alagoas) y el paisaje, teniendo en cuenta las posibles interacciones entre los espacios libres y la cultura popular. Se propone una reestructuración de los espacios libres en el barrio, considerándolos como elementos estructurales del paisaje, destacando las áreas con efervescencia cultural que se encuentran fragmentadas. Enfoques asociados con los espacios libres (socio-cultural: conservación de los procesos sociales y manifestaciones culturales) agregan valor con el potencial para promover la conexión entre las áreas verdes y las actividades culturales, promoviendo la convivencia colectiva en el paisaje y la permanencia de dichas manifestaciones culturales (folguedos) existentes. Por tanto, el objetivo es proponer una sistematización de los espacios libres públicos para atender a una demanda histórica y cultural para un uso colectivo, explorando las relaciones socio-espacial de los "folguedos" con el barrio y la ciudad, con el fin de contribuir a la protección de las manifestaciones culturales del barrio y, por lo tanto, adaptar la condición de recuperación urbana en la que actualmente se ve enfrentada.

PALABRAS CLAVE: Paisaje. Espacios libres. Folguedos (Manifestaciones culturales brasileñas). 


\section{INTRODUÇÃO}

Observa-se que a paisagem de um determinado lugar agrega variações espaciais e imateriais através do tempo, desempenhando importante função para a sociedade. "A paisagem nos permite apenas supor um passado. Se quisermos interpretar cada etapa da evolução social, cumpre-nos retomar a história que esses fragmentos de diferentes idades representam juntamente com a história tal como a sociedade a escreveu de momento em momento". (SANTOS, 1999, p. 86). Com isso, a paisagem mostra seu valor histórico. Deste modo, os valores materiais e imateriais da paisagem merecem intervenção que assegure a sua continuidade como referência cultural. As inquietações dessa dinâmica, sobre a qual os arquitetos e urbanistas têm a intenção de intervir por meio dos métodos de planejamento, refletem uma procura pela construção de um ambiente com característica estética, funcionalidade e legibilidade (Lynch, 1997), onde estas referências possam ser identificadas e valorizadas.

A paisagem é compreendida além de sua dimensão social, a partir também de sua construção cultural e simbólica. Denis Cosgrove (1998) ressalta que a paisagem vai além de seu aspecto físico e visual. Para o autor, a paisagem é mais do que o mundo que enxergamos, é um jeito de observá-lo. Deste modo a paisagem é um produto social, e consequência de uma modificação coletiva da natureza pelo homem. Seguindo este pensamento, Lúcia Costa (2006) também reforça o valor de se considerar a paisagem como uma construção cultural. Segundo a autora, refletir a paisagem dessa forma representa entendê-la como algo dinâmico e transformador, de enorme valor, não só como arquivo de aprendizado social e significado cultural, mas, ao mesmo tempo, por sua forte inspiração no costume de vida das pessoas.

Portanto, a paisagem apresenta duas dimensões que não são independentes: a material, física e a imaterial. Nota-se que a paisagem pode ser intermediada por meio da visão e entendimento das formas físicas de um determinado espaço, mas cada aspecto físico compreendido é carregado de símbolos e significados que exprimem a relação entre cultura e natureza. Estas relações se dão, além disso, por meio de uma sobreposição de ideias, crenças, valores e sentimentos vinculados à dimensão imaterial. Neste sentido, este estudo trata, sobretudo, da paisagem imaterial referente ao bairro Canafistula, que reflete suas manifestações culturais no espaço, através da dinâmica atual do lugar e também do desenvolvimento da cidade de Arapiraca-Alagoas, onde se localiza. Ademais, considerou-se pertinente trazer a definição do termo folguedos.

O município de Arapiraca apresenta uma grande diversidade de manifestações culturais que abrangem as quadrilhas juninas, cocos de rodas, guerreiros, reisados, destaladeiras de fumo, grupos teatrais, bandas de pífano, trios pé-de-serra, grupos de capoeira e festa religiosas (ver mapa 1). Estas manifestações, ao passar do tempo, se espalharam em vários bairros da cidade, sendo que estão presentes em maior quantidade nos bairros da Canafístula, Primavera e Baixão. Além disso, o município de Arapiraca proporciona uma boa variedade de atividades artesanais, tendo destaque o bordado, que é desenvolvido em quase todos os bairros e, principalmente, na Canafístula.

As manifestações culturais fazem parte e contribuem para a construção da paisagem. Por sua vez, o bairro Canafístula, em Arapiraca, abriga uma população com grande efervescência cultural apesar de não possuir estrutura física que acolha as práticas sociais que nele tomam lugar. Tal situação vem contribuindo para diminuir essas manifestações culturais. A paisagem, tendo como foco a relação sociocultural desses grupos, poderia contribuir para preservar e 


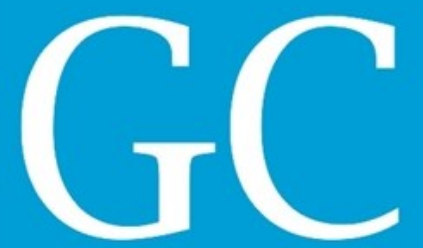

Revista Nacional de Gerenciamento de Cidades National Journal of Cities Managemen

manter essa efervescência cultural, auxiliando na manifestação das práticas sociais e afetivas do lugar.

Mapa 1: Localização dos Folguedos existentes e suas apresentações no município de Arapiraca

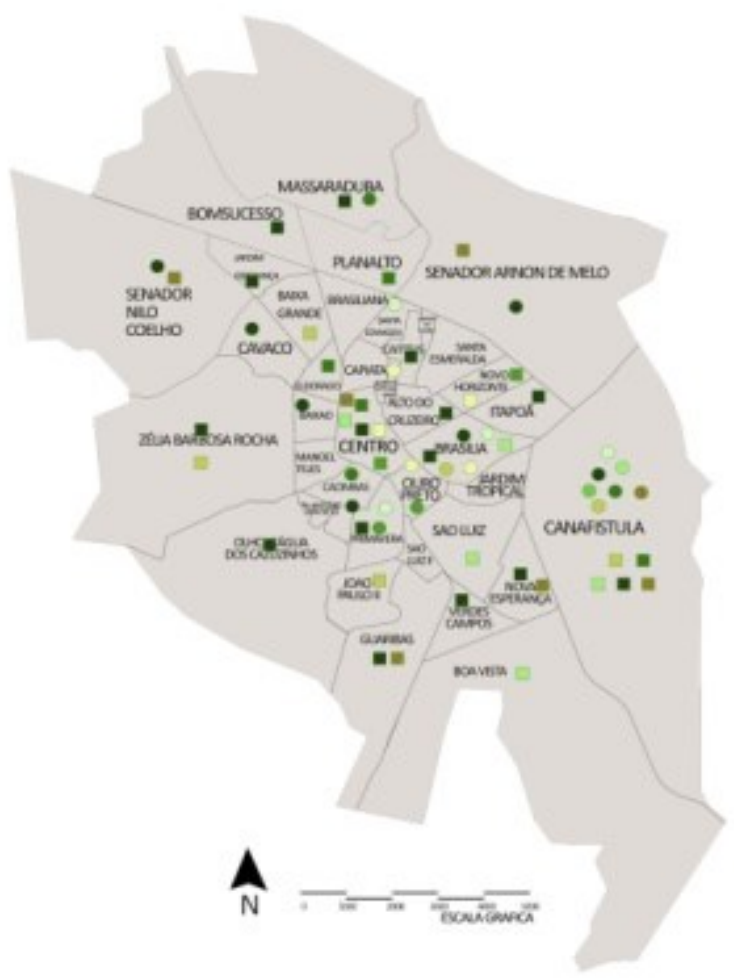

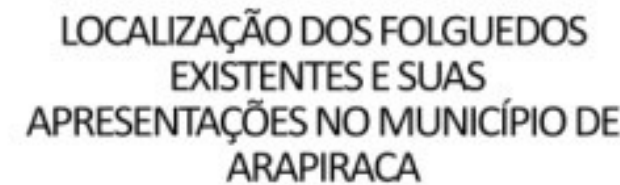

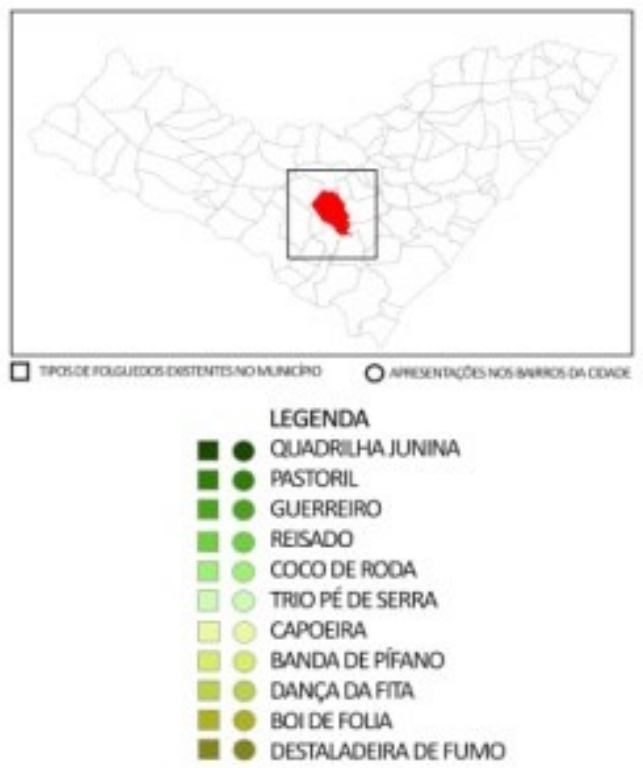

Fonte: AUTOR, 2015.

A Canafístula é um dos primeiros bairros da cidade de Arapiraca, possuindo mais de cem anos de existência. Está localizado na periferia, na divisa na zona urbana com a zona rural (ver mapa 2). O bairro é talvez o mais significativo espaço de cultura popular no município, sendo referência em manifestações de folguedos. Entretanto, observa-se que, recentemente, as manifestações culturais vêm diminuindo. Estas manifestações, os folguedos e o seu espaço de atividades culturais, aportam forte identidade ao bairro, estabelecendo significado de pertencimento aos moradores. 


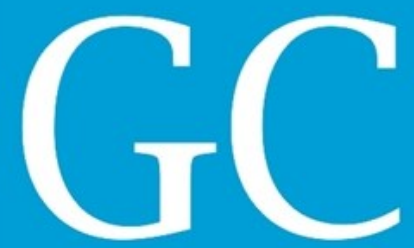

Revista Nacional de Gerenciamento de Cidades

Mapa 2: Localização dos Folguedos existentes e suas apresentações no município de Arapiraca

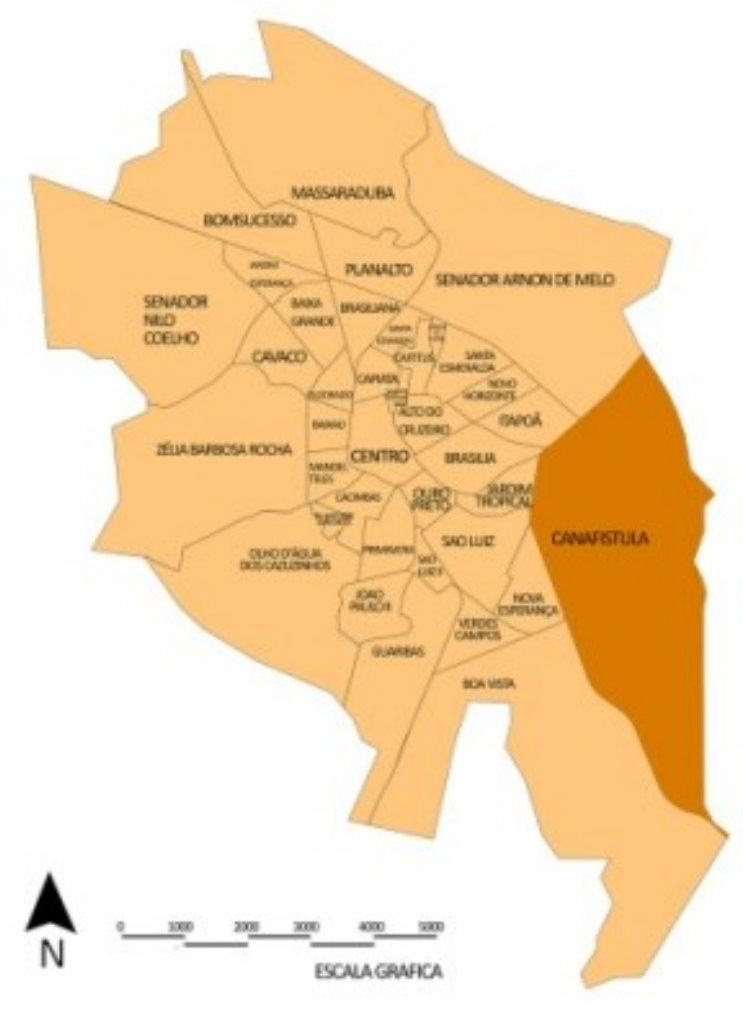

\section{MAPA DE LOCALIZAC̄̃̃O DOS BAIRROS NO MUNICÍPIO DE ARAPIRACA}

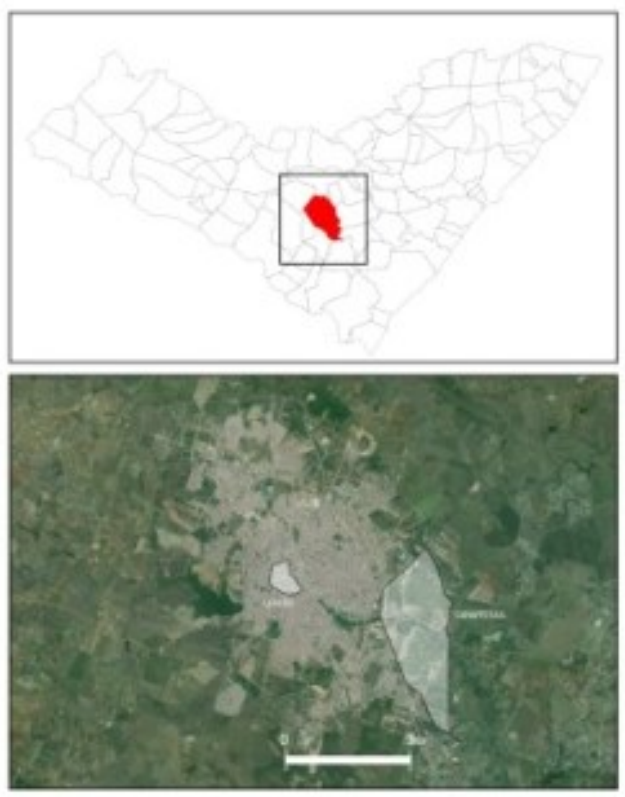

Fonte: ADAPTADO DO GOOGLE EARTH, 2016.

Entretanto, observa-se que, recentemente, as manifestações culturais vêm diminuindo, em função deste esvaziamento, o sentimento de pertencer ao bairro já não é mais o mesmo, devido a uma complexa trama de socialização entre moradores do local. A tendência à homogeneização cultural tem minimizado a relação dos folguedos com o lugar. É o esvaziamento das manifestações culturais em sentido simbólico, ou seja, é o deslocamento das ações culturais para novas mudanças.

Acredita-se que o uso adequado de espaços públicos estabelece uma relação importante entre moradores e os folguedos. A preservação e a construção de novos espaços públicos podem auxiliar a manter a história dos folguedos, característicos do lugar, contribuindo com seus valores urbanos e sociais no espaço de convivência. Neste sentido, discute-se a paisagem como parte da construção das manifestações culturais, identificando-a com seus valores regionais e as infraestruturas de apoio, elementos implantados ao longo do tempo, e que serão fundamentais para o desenvolvimento da área estudada. 


\section{OBJETIVOS}

\section{Objetivo Geral}

Propor uma sistematização dos espaços livres públicos para atender a uma demanda histórica e cultural de uso coletivo, explorando as relações socioespaciais dos folguedos com o bairro da Canafístula e a cidade Arapiraca-AL.

\section{Objetivos Específicos}

- Investigar as relações dos moradores do bairro com os grupos folclóricos,

- Apontar estratégias de consolidação do bairro da Canafístula como reduto de ponto de cultura popular no município;

- Compreender de que modo a área de estudo dialoga com os folguedos e a cidade;

- Conectar as áreas onde se realizam os eventos folclóricos com o restante dos espaços públicos da cidade;

- Reverter o processo de degradação ambiental urbana e isolamento do rio Piauí integrando-o à paisagem da cidade.

\section{METODOLOGIA}

A estratégia que embasou nossa pesquisa pautou-se na estrutura de compreensão da paisagem em matrizes de Kongjian Yu, citada. A pesquisa foi desenvolvida considerando-se a matriz natural e a matriz cultural. Para a matriz natural, procedeu-se à leitura da área de estudo em suas duas escalas, de bairro e de cidade, baseados nas camadas propostas por lan McHarg (1969) e os aspectos biofísicos de Tardin (2008), cumprindo uma primeira etapa da compreensão destas matrizes da paisagem. Num segundo momento, procedeu-se a um aprofundamento da matriz cultural com o foco na compreensão das manifestações dos folguedos e sua relação com a população.

Adotaram-se na metodologia três escalas distintas de intervenção: a primeira escala, da cidade que conduz a compreensão e análise, propondo diretrizes para o bairro Canafístula. As diretrizes e análises pretendem orientar o olhar para o espaço urbano conduzindo-o para a sistematização dos espaços públicos que correspondam às demandas funcionais da cidade, tendo as questões do bairro como referência, buscando garantir a coerência entre as escalas da cidade e do bairro. A segunda é a escala do bairro, envolvendo a análise dos espaços livres e apresentação de proposta de sistematização dos mesmos com o foco para atendimento às necessidades da população e ampliação das manifestações culturais específicas - os folguedos - do bairro Canafístula.

E por último, a escala local, buscando um direcionamento propositivo para solução de alguns 
espaços visando à conjunção das atividades cotidianas dos habitantes e de realização dos folguedos, em uma visão compartilhada que reforça a importância de se pensar nas manifestações culturais como elemento essencial na construção da paisagem, criando condições para salvaguardar a cultura popular do bairro. E com isso, serem valorizadas e compreendidas como um grande patrimônio imaterial simbólico do bairro Canafístula e também da cidade do qual não se pode abrir mão. Para isso, torna-se imprescindível a difusão do saber cultural, através dos seus mestres, artistas e integrantes nos seus respectivos saberes inerentes aos diversos tipos de folguedos.

\section{MÉTODO DE ANÁLISE}

Através dos conteúdos coletados, passou-se à identificação dos problemas e potencialidades referentes à realização e preservação dos processos naturais e culturais existentes: estéticos, simbólicos, religiosos, de convivência social e analisar a relevância dos resultados a serem utilizados na proposta.

\section{CANAFÍSTULA ESPLENDOR CULTURAL - OS FOLGUEDOS}

Trata-se como se sabe, que os folguedos contribuem na valorização da cultura popular do bairro, procurando envolver o fator histórico do lugar não só nas atividades desenvolvidas pelos mesmos, mas também como uma forma de atrair a comunidade, para que haja uma maior interação entre os moradores e os brincantes dos folguedos. Todavia, quando se procura resgatar os valores culturais, deve-se também acompanhar as novas formas de tecnologia, e a cultura e o lugar são dois conceitos importantes para melhor pensar em como introduzir esses novos avanços. É importante observar que muitas vezes a cultura popular embora presente nas manifestações do povo, na memória coletiva, não recebe a devida atenção dos próprios moradores e acaba restrita a espaços insuficientes ou desvalorizados como expressão de pouco valor. Em geral todos os folguedos que serão apresentados a seguir têm uma memória afetiva com o lugar, principalmente em manter a cultura popular viva e presente no bairro.

Considerou-se pertinente a definição do termo folguedos. Conforme ressalta Lourdes Macena (2003), folguedos são festas populares cuja principal particularidade é a presença da dança, da música, e a representação teatral. A maior parte dos folguedos tem origem religiosa, portuguesa, católica ou de cultos africanos, indígena, e outras são folclóricas. Trata-se, sobretudo, que muitos folguedos foram com o passar do tempo, aderindo às mudanças culturais e acrescentando, às festas, novas vestimentas, (fitas e roupas coloridas), coreografias sincronizadas e grandes cenários. Nota-se que os folguedos compõem parte da cultura popular de Arapiraca, mais é no bairro Canafístula onde se destacam. A seguir, vamos apresentar a cronologia dos folguedos da Canafístula, sua definição segunda memória coletiva dos moradores e apresentar os lugares do em que estes folguedos acontecem. 
10 - Reisado em 1930 - De origem Portuguesa, o reisado é uma obra sacro profana constituída de brincantes e cantores que representam as jornadas de cada canto. Com figurino combinado de azul e de vermelho, saia, manto, espada, chocalho e chapéu em formato de igreja, o reisado da Canafístula ainda mantém sua característica peculiar.

20 - Pastoril em 1940 - O pastoril surgiu como forma de homenagear o menino Jesus. Seus cantos e letras estão relacionados ao seu nascimento que retratam também sua passagem. $\mathrm{E}$ assim a festa natalina encontrou uma de suas formas culturais.

3o - Quadrilha Junina em 1984 - No Nordeste a Quadrilha Junina foi introduzida como dança de salão, principalmente nas salas de reboco e logo foram adaptadas e moldadas conforme o desejo popular. No início eram compostas de brincantes matutos, vestimentas de xadrez e chitão que remetiam à vida rural.

4 - - Dança da Fita em 1985 - Segundo moradores, este folguedo representa o plantio de árvore e, sobretudo, a época de floração de todas as espécies vegetais. É necessário um mastro de $3 \mathrm{~m}$ com fitas largas coloridas para a sua execução e em geral é composta de 12 crianças que seguram na ponta de cada fita, girando em torno do mastro e traçando a fita ao som da música.

5o - Coco de Roda em 2000 - É um folguedo puramente alagoano que representa um típico sapateado, e que em geral é muito utilizado durante a construção de casa de barro em quase todo o nordeste brasileiro. É constituído geralmente por sete pares que dançam em forma de círculo e linear.

60 - Destaledeira de Fumo em 2006 - É um folguedo genuinamente arapiraquense, são senhoras entre 48 a 78 anos de idade que retiram os talos das folhas de fumo. Durante a colheita do fumo, as senhoras se reúnem nos salões para trabalharem na destalagem e durante o trabalho entoam versos das cantigas, em várias vozes formando um coro, aonde nos salões os cantos eram sem instrumentos musicais e atualmente são acompanhados por sanfona, triângulo e zabumba.

Pode-se afirmar que o fato de haver diferentes percursos para os folguedos no bairro seja um elemento que contribua para o enriquecimento patrimônio cultural da cidade e se configure como mais uma ferramenta de identificação dos folguedos para que possa ser compreendido como preservação de sua memória coletiva (ver mapa 3). 


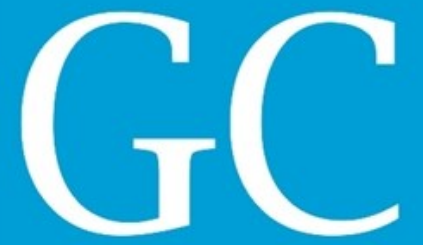

Revista Nacional de

Mapa 3 - Diferentes percursos dos Folguedos.

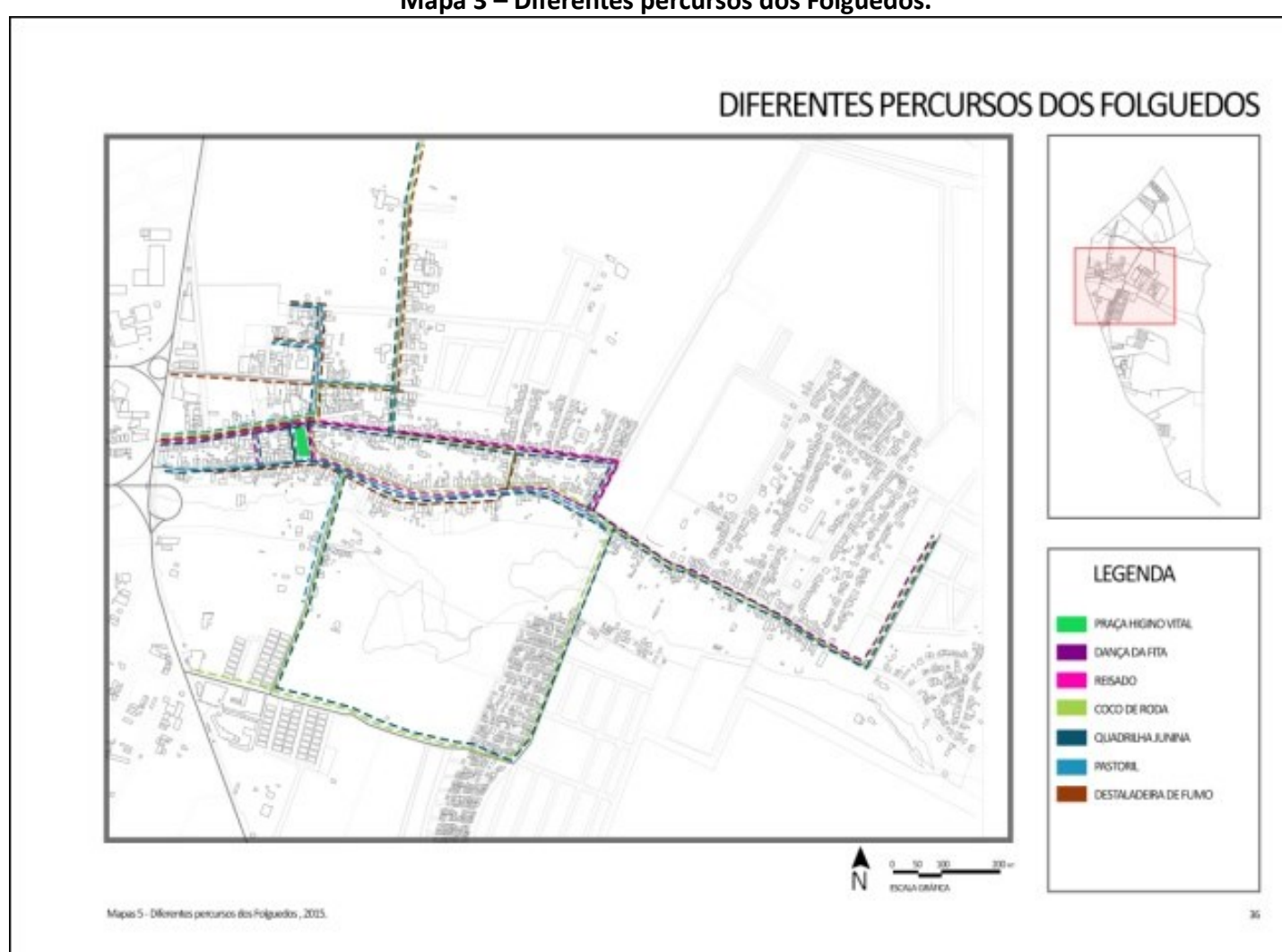

Fonte: AUTOR, 2015.

Em síntese, os principais espaços históricos do bairro são a Praça, Igreja Católica Santa Isabel da Hungria, Sede Comunitária, Escola Municipal Domingos Lopes, Escola Estadual Moacir Teófilo, Creche Rotary Geraldo Silva e o Posto Unidade Básica de Saúde. Esses pontos estabelecem um forte vínculo com os folguedos, seja de memória urbana, já que os mesmos fazem alguma atividade cultural neste espaço público. 


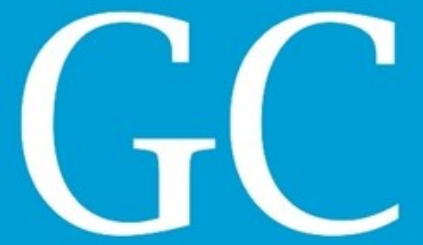

Revista Nacional de Gerenciamento de Cidades

Mapa 4 - Espaços relevantes para os Folguedos.

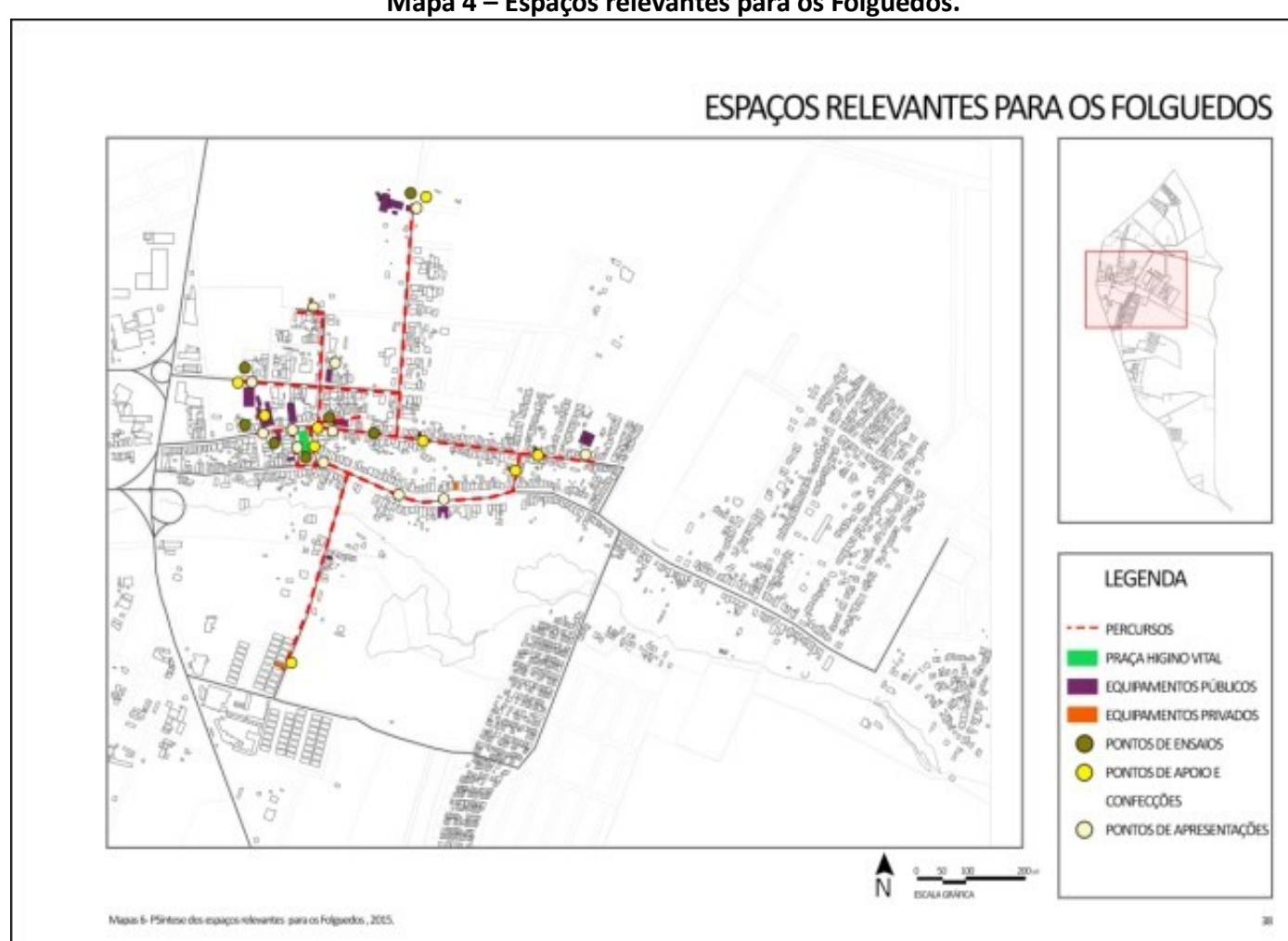

Fonte: AUTOR, 2015.

Conforme mostra o mapa 4 acima, a Praça Higino Vital é um dos mais importantes e significativos espaços do bairro, a mesma é denominada pelos moradores como "Praça dos Folguedos", local onde ocorrem diversos tipos de eventos como, por exemplo, apresentações culturais, bingos beneficentes, teatro ao ar livre, Festa da Padroeira Santa Isabel, Festa do São João da Canafístula e é também local de ensaio de vários folguedos. Os pontos fixos são utilizados por todos os folguedos, já os pontos itinerantes são locais de elaboração de figurino e também dão suporte às manifestações culturais do bairro. Os pontos móveis são estruturas montadas em determinada época do ano para as diversas apresentações no bairro (ver mapa 5). Em resumo final, criam-se oportunidades de identificação através do folguedo, de reconhecimento e crescimento, agregando todos os brincantes. 


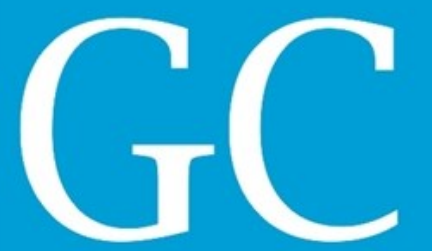

Revista Nacional de Gerenciamento de Cidades National sournal of Cities Management

Mapa 5 - Espaços relevantes para os Folguedos.

\section{MAPA DE PERCURSO DOS FOLGUEDOSE MANIFESTAÇÕES}
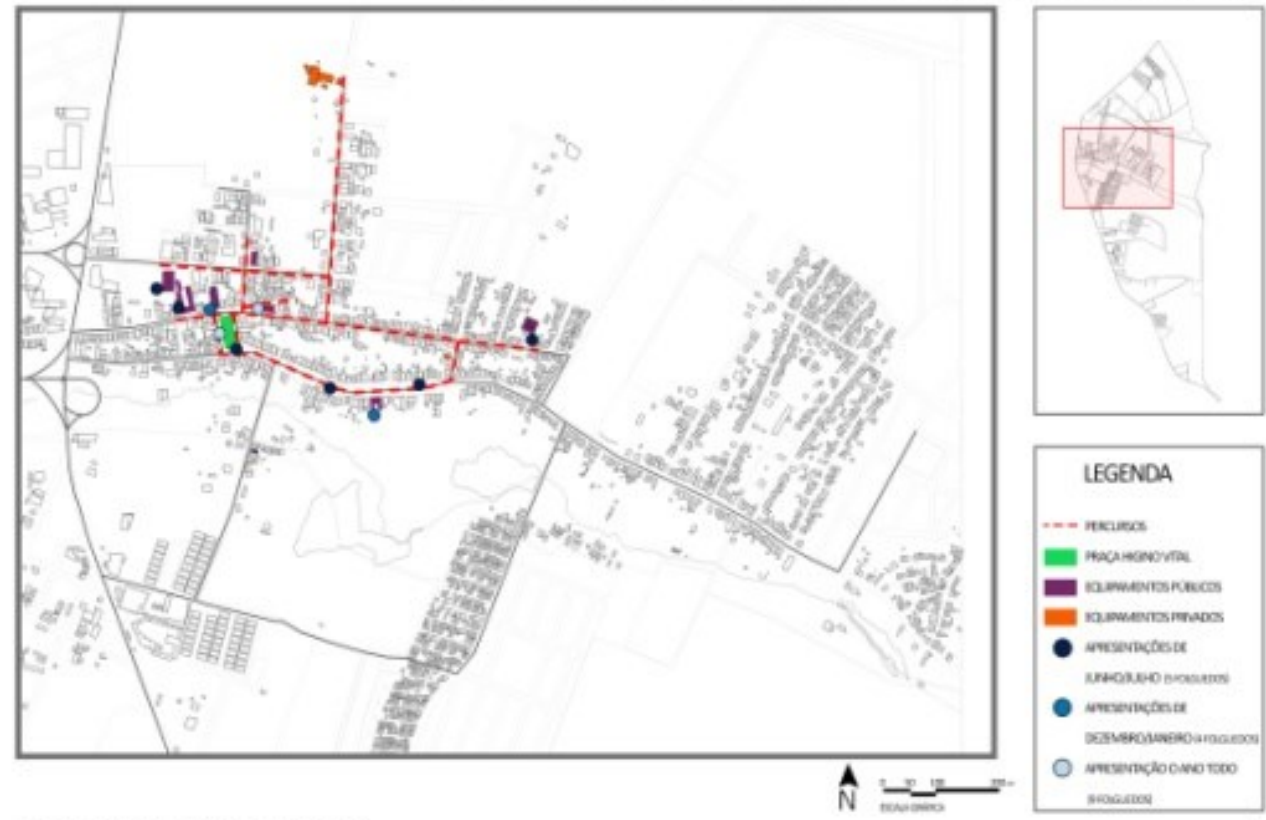

Fonte: AUTOR, 2015

\section{CARACTERÍSTICA DO LUGAR}

Aborda-se uma análise e reflexão sobre o bairro Canafístula e seus arredores com a identificação de problemas e potencialidades referentes à realização e preservação dos processos naturais existentes: as dinâmicas da água, da vegetação, da topografia e dos solos e suas interfaces positivas ou negativas com as edificações, os espaços livres e as vias. 
Mapa 6: Análises das abordagens biofísicas do recorte espacial do Bairro Canafístula

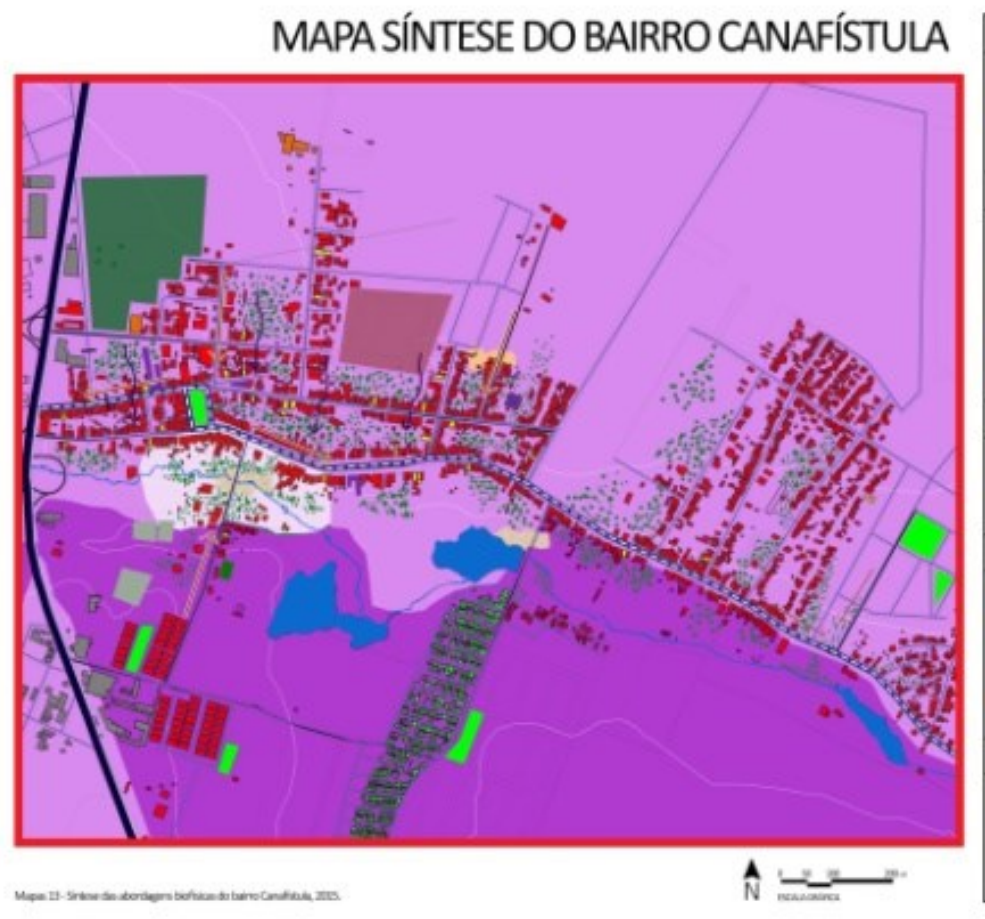

\begin{tabular}{|c|c|}
\hline & AGUA \\
\hline \multirow{3}{*}{$\overline{0}$} & nopred \\
\hline & noconuenco \\
\hline & 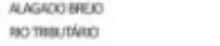 \\
\hline & VEGETAÇO \\
\hline$=$ & 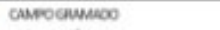 \\
\hline - & nabosecaclo \\
\hline$=$ & Mensecal \\
\hline = & hathaciocona \\
\hline$=1$ & Latanesmoca \\
\hline$=$ & Aathocomatos \\
\hline \multirow[t]{2}{*}{$=$} & mages \\
\hline & TOPOCRAFIA \\
\hline$=$ & 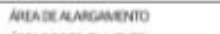 \\
\hline$=$ & Aathorocsearento \\
\hline & ACOMOUE DESCI \\
\hline & EDIFACACŌES \\
\hline$=$ & Gnsmaven \\
\hline$=$ & sursasubar \\
\hline = & concoveno \\
\hline$\square$ & 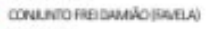 \\
\hline = & combeco \\
\hline$=$ & sencoso \\
\hline \multirow{2}{*}{$=$} & BQuPANentos PLiBucos \\
\hline & vas \\
\hline - & 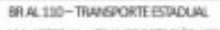 \\
\hline- & 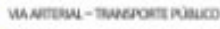 \\
\hline - & wheconoka \\
\hline & wasiocas \\
\hline 0 & MeE wiano \\
\hline
\end{tabular}

Fonte: AUTOR, 2015.

Ao fazer uma análise do elemento água, percebe-se a ocupação das margens do rio por moradias irregulares, o lançamento de esgoto domiciliar, entre outros dejetos, o que causou a submissão dos recursos naturais local. Como a área é cortada pelo rio, há degradação das margens. Na cobertura vegetal do bairro, predominam as áreas de mata seca. A vegetação natural é diversificada sendo encontrada a maior parte no fundo das residências.

Pode-se afirmar que, considerando a topografia, com predominância plana, o bairro é favorável à expansão urbana. No aspecto da edificação, há o problema da ocupação das margens do rio por moradias irregulares e também por assentamentos precários. De uma forma geral, verificase a carência de equipamentos públicos. A mobilidade urbana do bairro tem sido atualmente favorecida pelo asfaltamento de vias periféricas, distanciando a circulação viária do centro da cidade e desafogando o tráfego viário principal. Entretanto, o bairro possui uma estrutura viária precária, com boa parte das vias urbanas sem pavimentação, o que tem impedido de gerar uma política de transporte coletivo eficiente.

\section{Espaços Livres de Arapiraca}

Caberia, igualmente, destacar o discurso de Raquel Tardin (2008) a respeito dos espaços livres, enfatizando o valor que eles desempenham sobre a percepção da paisagem. São eles que 
permitem os vínculos entre os componentes territoriais, traçando uma imagem de lugar. Por sua vez, a autora ressalta, ainda, que apresentam um forte potencial de mudança, representando os elementos mais flexíveis do território e do seu espaço, e, além disso, os mais frágeis e mais sujeitos a passarem por mudanças ao longo do tempo, seja em função da urbanização ou das transformações dos seus elementos biofísicos e sócio-culturais.

Os principais espaços livres de Arapiraca representam as manifestações que refletem uma mistura de culturas, relembram antigos costumes e modos de trabalho evidenciando a força das tradições populares na cidade. Essas manifestações estão presentes tanto nos festejos juninos como também nas festas de padroeira, na paixão de Cristo e ciclo natalino. Fazem parte da vida cultural do lugar, além de celebrar a fé, e reforçar temas históricos, como a semana da consciência negra, dentre outros eventos culturais. Os principais lugares de cultura na cidade de Arapiraca estão localizados a uma distância grande do bairro da Canafístula, o que, por condições de falta de infraestrutura urbana de transporte, não permite que a produção cultural do bairro se conecte aos pontos centrais da cultura no município.

Mapa 7: Tipologias dos Espaços Livres de Arapiraca
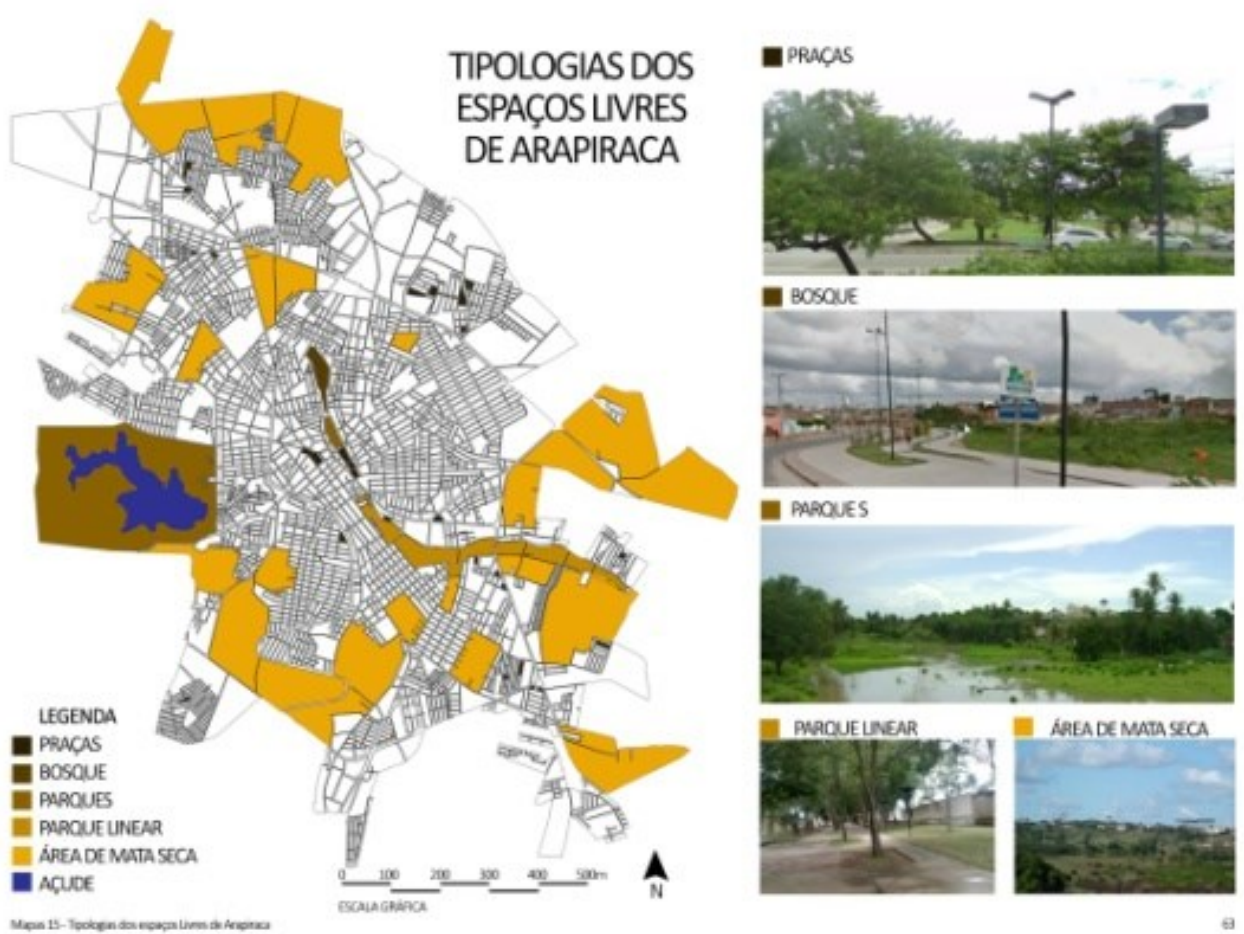

Fonte: AUTOR, 2016.

No espaço urbano do bairro, segundo a Prefeitura Municipal de Arapiraca, somente $1,9 \%$ da área total é ocupada por edificações públicas (seis equipamentos públicos) e espaços livres públicos. Os espaços livres públicos que, em geral, se encontram na área central do bairro, 
pouco ocupados pelos moradores já que os mesmos só possuem a delimitação do espaço, sem um projeto paisagístico adequado que atenda às necessidades da população local.

Percebe-se, no entanto, que estes dados do mapa 7, a seguir, são reveladores da necessidade de intervenção pública, no sentido de adotar leis e normas mais eficientes que revejam a destinação destes espaços livres, com proposta paisagística, contando com a participação da comunidade que possam, sobretudo, enaltecer a cultura popular do lugar. Esta realidade sinaliza a importância deste estudo, no sentido de contribuir com propostas de espaços livres para a cidade.

Mapa 8: Tipologias dos Espaços Livres Públicos do bairro Canafístula
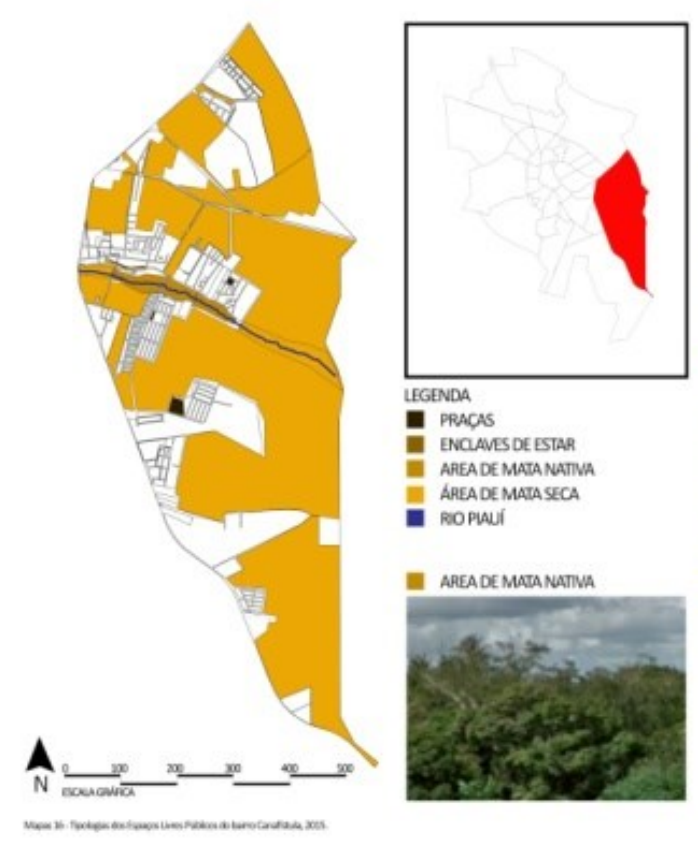

TIPOLOGIASDOS ESPAÇOS LIVRES PÚBLICOS DO BAIRRO - precos CANAFístULLA

Fonte: AUTOR, 2016.

\section{RESULTADO}

Levando-se, em consideração esses aspectos, foram feitas direcionamentos urbanísticos (projetos estruturantes), o primeiro foi a criação de um Centro Cultural no bairro Canafístula, visando-se promover o fortalecimento da identidade cultural dos folguedos, do local e também do município. Com espaço para exposições, apresentações, ensaios, livraria-café e alameda de serviços. O segundo, a criação de um percurso da Memória Cultural e Histórico do bairro Canafístula, que será uma maneira transmitir a história, memória e identidade do lugar, além de fortalecer o turismo da cidade. Onde durante o passeio passaram por marcos, por exemplo, praça, igreja, sede comunitária, vila do artesanato, casas dos mestres, cooperativas e centro cultural. $O$ terceiro a construção de um Pavilhão Cultural como segundo ponto de apoio aos 
folguedos, proporcionar a comunidade, de diferentes níveis socais, a possibilidade da participação em atividade culturais. O quarto a criação de uma Vila de Artesanatos, a partir de casas existentes no bairro, gerando fonte de renda, trabalho e divulgação do artesanato local. $\mathrm{E}$ por fim, a criação de ciclovias, estacionamentos, melhorias na sinalização, tanto vertical, como horizontal, e a melhoria da pavimentação.

Como resultado final foi proposto às principais diretrizes para os Espaços Livres de Arapiraca, em consonância e em complementação ao Plano Diretor de Arapiraca. No âmbito ambiental: Conexão dos Espaços Livres, Criação do Parque Linear, Criação de um Programa de Preservação Ambiental. No aspecto Interesse Social e Cultural: Criação de novas áreas verdes de lazer em pontos poucos atendidos, Criação um de sistema de áreas de eventos culturais com identidade comum, totens informativos, facilitando a visitação turística e estabelecendo as conexões entre as mesmas (ver mapa 9).

\section{Mapa 9: Percurso Cultural da Cidade e Parque Linear}
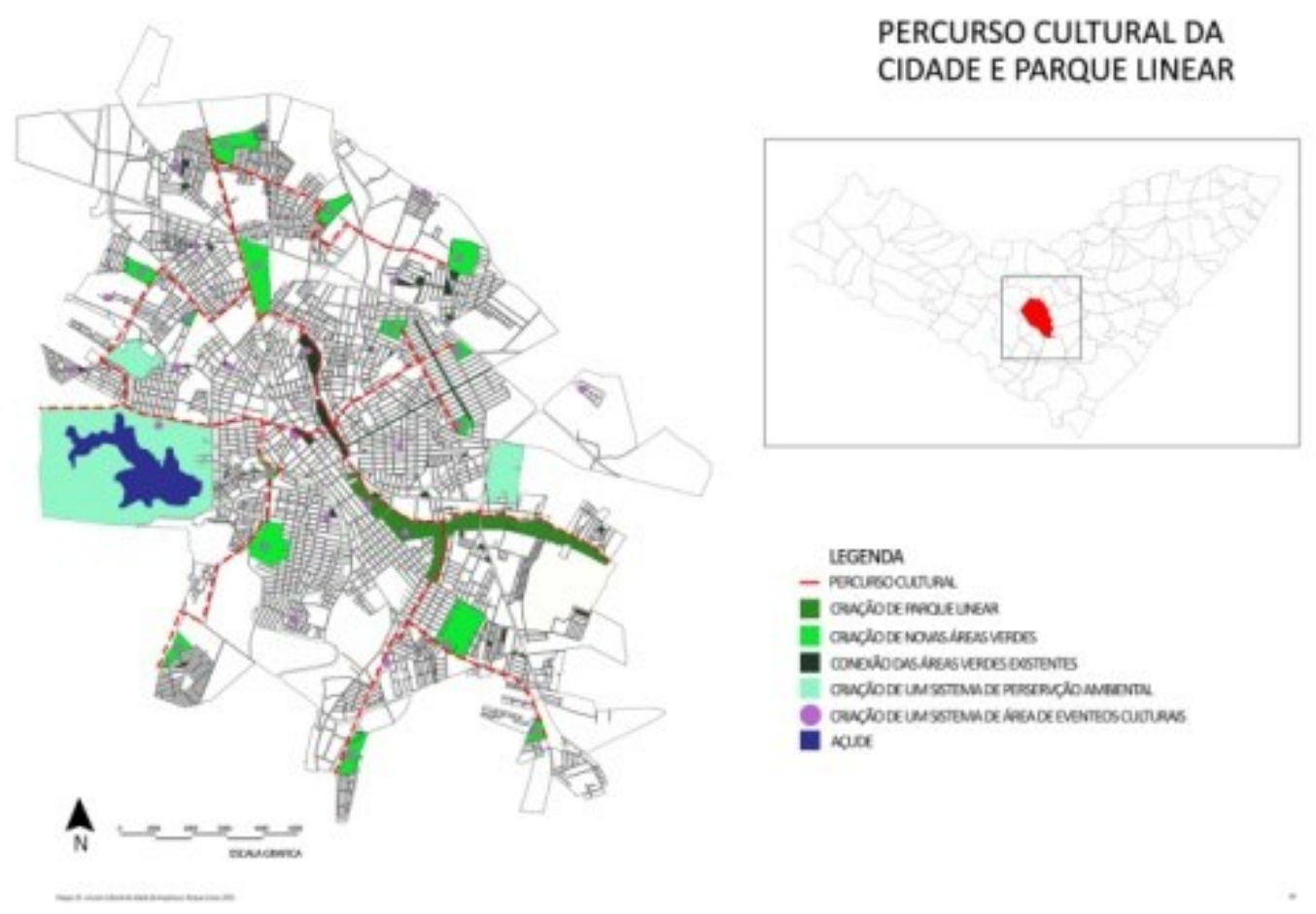

- onctiodenecueinesa

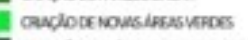

- coveloosivesveros perients

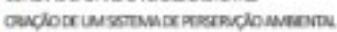

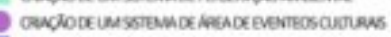

acos

Fonte: AUTOR, 2016.

Para os Espaços Livres de Canafístula a intervenção sugerida envolve duas linhas de atuação: Revalorizar e conectar os espaços livres públicos, Fortalecer o patrimônio histórico-cultural. 
A ligação entre o Percurso Cultural e o Parque procura trazer um deslocamento funcional entre partes sob outra perspectiva: o caminhar aqui se desenvolve em percurso diferenciado e arborizado, uma experiência que visualiza diferentes espacialidades: construções históricas casa de farinha, igreja, casa de mestres dos folguedos, casa museu, sede comunitária, vila de artesanatos, trilha ecológica, horta comunitária, espaços de piquenique, infantil, de jogos, ambiental, praça das esculturas, praça cultural, caminhos dos namorados, dos poetas, espaços esportivos, trilha ecológica, quiosques, bicicletário, coreto, mirante, que serão pontos importantes de referencia da comunidade. (ver mapa 10).

Mapa 10: Compreensão das camadas em matrizes

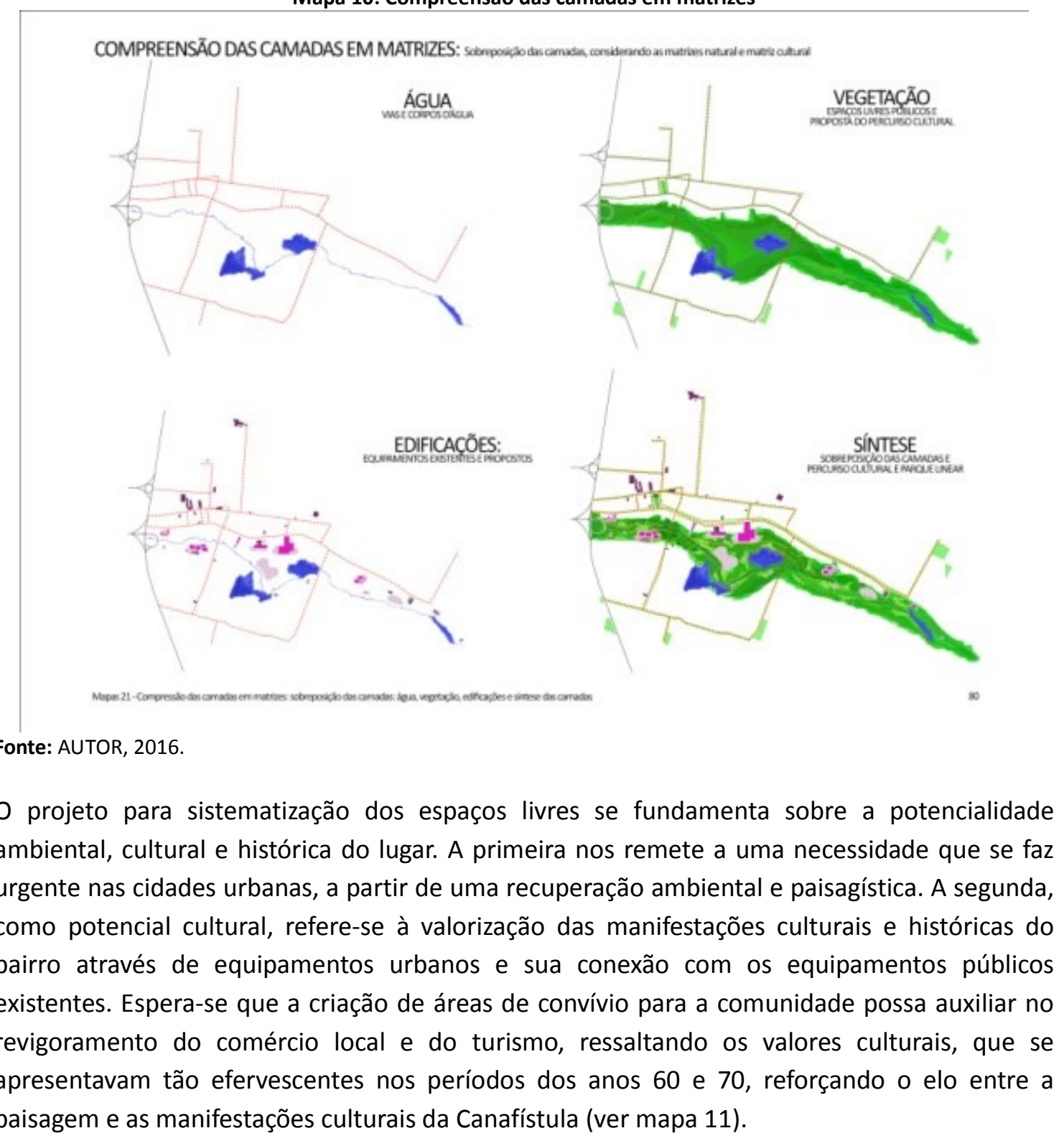




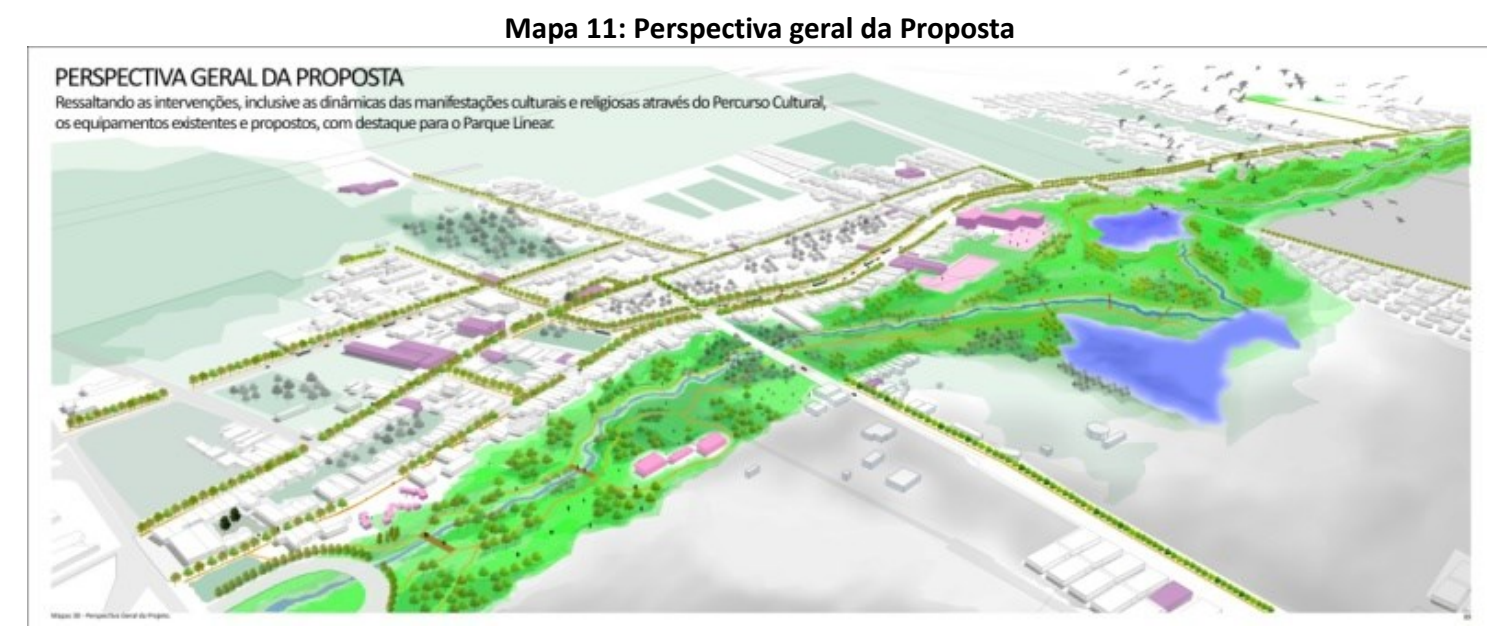

Fonte: AUTOR, 2016.

\section{CONCLUSÃO}

Esta pesquisa reflete sobre e propõe a intervenção na paisagem do bairro de Canafistula, em Arapiraca, a partir de uma abordagem ambiental e cultural, em consonância com as tendências contemporâneas do projeto paisagístico. Foi construída e elaborada a partir da formulação de um aporte teórico metodológico, desenvolvido na revisão bibliográfica, fundamental para a percepção dos níveis de conexão e fragmentação diagnosticados na pesquisa de campo para a elaboração da proposta do trabalho. Desta forma, foi fundamental o estudo da compreensão da paisagem em matrizes, baseado na sobreposição de camadas, mostrando-se essencial para entendimento da dinâmica da paisagem em sua complexidade, assim como também em um melhor entendimento do processo de restruturação dos espaços livres na área.

A relevância atual do bairro Canafístula e de sua cultura está na importância identitária das manifestações culturais para a cidade e principalmente para próprio bairro. Os folguedos são considerados um patrimônio cultural relevante e movimenta toda comunidade, além daqueles que participam em sua representação, como também em toda a sua implantação, como artesãos, costureiras, doceiras, dentre outros empreendedores. Cabe ressaltar, neste contexto do espaço urbano, que é necessário promover a identidade do lugar através da sua cultura popular. Desta maneira, podem-se agregar os folguedos para evidenciar os espaços livres dedicados para a cultura, transformando-se assim em local atrativo para receber qualquer tipo de expressão cultural, principalmente atraindo o público para uma maior interação com as manifestações culturais do bairro.

Tendo como foco as matrizes naturais e culturais, a pesquisa colocou em evidência as divergências entre os moradores que vivem às margens do rio Piauí, em relação ao impacto ambiental causado pela transformação da paisagem local em decorrência da formação de assentamentos precários, popularmente chamados de conjuntos. A partir deste trabalho, 
entretanto, observou-se a percepção ambiental dos moradores, revelando um grau de preocupação com os recursos naturais.

A sistematização dos espaços livres do bairro foi definida por questões culturais e ambientais relacionadas a diferentes abordagens e visando desenvolver intervenções para suprir as carências de cada área. A proposta criou mecanismo para valorização e reconhecimento das manifestações culturais, sobretudo os folguedos, a fim de alcançar a melhoria contínua, focando sempre no fortalecimento cultural e também na qualidade de vida dos moradores, no equilíbrio ambiental e no atendimento às normativas urbanas.

\section{REFERÊNCIAS BIBLIOGRÁFICAS}

ARAPIRACA. Prefeitura. Plano Diretor Participativo. Lei 2424, de 23 de Janeiro de 2006 - Art.90

CAUQUELIN, Anne. A Invenção da Paisagem. Tradução: Marcos Marcionilo. São Paulo: Martins Fontes, 2007.

COSGROVE, D. (1984). Social Formation and Symbolic Landscape. Wisconsin: Wisconsin Press, 1998.

COSTA, Lucia Maria Sá Antunes. A Paisagem em movimento. In: MACHADO, Denise Barcellos Pinheiro. (Org.). Sobre Urbanismo. Rio de Janeiro: Viana \& Mosley PROURB, 2006, p. 149-157.

CORNER, James (1999). “The agency of mapping: speculation, critique and invention”, in Cosgrove, Denis, ed. Mappings, Londres, Reaktion Books, 213-252.

CORNER, James (1999). "Recovering Landscape as a Critical Cultural Practice”, in Corner, James, ed., Recove-ring Landscape: Essays in Contemporary Landscape Architecture, New York, Princeton Architectural Press, 1-28.

DI FIDIO, M. Architettura del Paesaggio. 3 ed. Milano: Pirola Editores, 1990.

GERALDO, J. C. A Evolução dos Espaços Livres Públicos de Barueru Brotas e Dois Córregos - SP. 1997. 207F. Dissertação (Mestrado em Geografia Física) - Faculdade de Filosofia, São Paulo, 1997

LYNCH, Kevin. A Imagem da Cidade. São Paulo: Martins Fontes, 1997.

LYNCH, K. A Theory of Good City Form. Cambridge, MA: The M.I.T. Press, 1982.

MACENA, Lourdes. Festas, Danças e Folguedos: Elementos de identidade local, patrimônio imaterial do nosso povo. In: MARTINS, Clerton (org). Turismo, Cultura e Identidade. São Paulo: Roca, 2003.

MASSEY, D. Imagining the World. In Allen J. and Massey, D. (eds.) Geographical Worlds, Oxford: Oxford University Press/The Open University. 1995.

MCHARG, lan L. Design with Nature. John Wiley \& Sons, Inc., 1992.

PANERAI, Philippe. Análise Urbana. Brasília: UNB, 2006. Universidade Federal do Rio de Janeiro, 2003.

POCHE, B. "Vne definition sociologique de la region". In: CAHIERS INTERNATIONAUX DE SOCIOLOGIE, Paris, n. 79, 1985.

SOUZA, MARCELO JOSÉ LOPES DE, O Território: sobre o Espaço e poder, autonomia e desenvolvimento. In CASTRO, Iná Elias de et al. Geografia Conceitos e Temas. 3a ed. Rio de janeiro: Bertrand Brasil, 2001. 


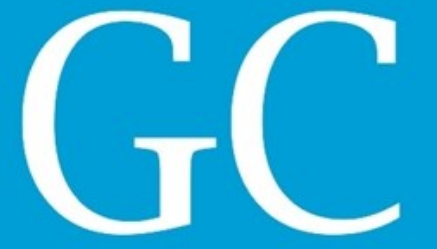

Revista Nacional de

Gerenciamento de Cidades

National Journal of Cities Management

SANTOS, Milton. Espaço e método. São Paulo: Nobel, 1985. 88 p.

SERPA, Angelo. O Espaço Público na Cidade Contemporânea. waterfronts>. Acesso em: maio. 2015. Salvador: EDUFBA, 2007.

TUAN, Yi-Fu. Espaço e Lugar: a perspectiva da experiência. Tradução de Lívia de Oliveira. São Paulo: DIFEL. 1983.

TARDIN, Raquel. Espaços livres: Sistema e Projeto Territorial. Rio de Janeiro: 7Letras, 2008.

YU, KONGJIAN e Padua, Maria. The Art of Survival - Recovering Landscape Architecture. The Images Publishing Group Pty, Victoria, 2006. 